\title{
FOLKLORE Y LINGÜÍSTICA
}

\author{
Esteban Tomás Montoro del Arco \\ Universidad de Granada \\ montoro@ugr.es
}

\begin{abstract}
Resumen
El Folklore es un movimiento erudito europeo que surge en el último tercio del siglo XIX con el objetivo de estudiar desde un punto de vista científico los conocimientos y manifestaciones más genuinas del pueblo. Coincide con los comienzos de la Antropología y de la Etnografía, y aunque se basó en las ideas románticas de nación y pueblo, asumió al mismo tiempo las ideas más avanzadas de la época, como el Positivismo y el Evolucionismo social. Dado su interés por las formas de expresión popular, los folkloristas tuvieron siempre presente el estudio de lo lingüístico, aunque, sin embargo, no recibió la misma atención en todos los países. Mantuvo una relación próxima con las disciplinas lingüísticas más características del XIX, como la Filología histórica y comparada, la Dialectología y la Paremiología, aunque esta conexión no ha recibido mucha atención hasta la fecha. En este trabajo mostraremos el lugar que ocupó lo lingüístico en la organización general y en la práctica de los estudios sobre el saber popular, su relación con las disciplinas más propiamente lingüísticas $y$, especialmente, el valor de este movimiento para la historia de la lingüística española.
\end{abstract}

PALABRAS CLAVE: Historiografía de la Lingüística, Folklore, Dialectología, siglo XIX.

\begin{abstract}
Folklore is a scholarly European movement that emerged in the last third of the $19^{\text {th }}$ century. Its aim is to study scientifically the most authentic expressions of different communities and their collective knowledge. It emerges at the same time as Anthropology and Ethnography and it incorporates not only the Romantic ideas about nations and ethnic groups, but also the latest ideas of the period, such as Positivism or Social Evolutionism. Folklorists always took into consideration the study of linguistic issues, as they considered them part of popular forms of expression, although they did not receive the same degree of attention in all countries. Folklore maintained a close relationship with those areas of linguistic research characteristic of the $19^{\text {th }}$ century, such as Historical Philology, Dialectology or Paremiology. However, the specific nature of this connection has not been examined yet. This paper will research the place of the linguistic element within the general disposition and practice of Folklore, its relationship with proper linguistic disciplines and, in particular, the value of Folklore to the History of Hispanic Linguistics.
\end{abstract}

KEY WORDS: Historiography of Linguistics, Folklore, Dialectology, $19^{\text {th }}$ century.

\section{Introducción}

A comienzos del siglo XIX se desató en Europa un creciente interés por lo popular que terminó consolidándose, ya mediada la centuria, en todo un 
movimiento que dio en llamarse Folklore ${ }^{1}$ y que se proponía estudiar los conocimientos y manifestaciones más genuinos del pueblo. El interés por este no era nuevo -hundía sus raíces en el Romanticismo-, pero los folkloristas quisieron abordarlo desde un punto de vista científico y acorde con las nuevas tendencias filosóficas, y para ello institucionalizaron y ordenaron su estudio. En primer lugar, desdoblaron el saber en dos vertientes, el saber culto y el saber popular, con lo que abrieron un campo de trabajo amplísimo, poco hollado y, por ende, altamente motivador; en segundo lugar, prepararon un ambicioso programa de investigación basado en una clasificación del saber popular que contemplaba tantas ramas folklóricas como ciencias en el saber culto: folklore literario, lingüístico, jurídico, de bellas artes, botánico, matemático, pedagógico, físico-químico, geográfico, médico, etc.

Aunque se basaron en los mismos presupuestos que el nuevo paradigma científico aplicado a las ciencias naturales -que terminaría revolucionando la ciencia misma-, los folkloristas no tuvieron la repercusión que esperaban. De hecho, la gran paradoja del estudio del Folklore consiste en haber nacido a partir de las ideas más avanzadas de la época y, sin embargo, haber sido desplazado progresivamente hasta ser percibido en la actualidad como la antítesis de la labor de investigación científica (cf. Velasco Maíllo, 1990). El objeto inicial de la investigación folklórica se ha diluido entre la Etnología, la Sociología o la Antropología social y cultural, disciplinas que surgieron en la misma época y que se consolidaron, en parte, gracias al influjo de la Filología Comparada, aunque aún hoy no se han definido claramente sus límites².

El Folklore incluyó en su programa lo que podemos llamar folklore lingüístico, esto es, actividades de recopilación y reflexión en torno a las manifestaciones lingüísticas que se consideraban propias del pueblo o de los pueblos. Al bucear en el pasado, comulgaba perfectamente con los presupuestos de la gramática histórica y comparada, que suponía la aplicación sistemática de una metodología científica en el examen de las lenguas y de las relaciones

1 Esta palabra terminó designando no solo al movimiento sino también al objeto de estudio. Esta última acepción es la más extendida hoy día. En lo sucesivo distinguiremos el folklore como movimiento, por un lado, y el folklore como objeto de estudio, por otro, mediante el uso de mayúsculas y minúsculas respectivamente (Folklore/folklore). Se respetará la ortografía original de las citas, así como el guion de separación que la palabra Folklore presenta en algunos casos (Folk-lore). Asimismo, hoy se prefiere la forma gráfica folclore, como muestra el DRAE (2001). Sin embargo, en este trabajo utilizaremos la grafía original con el objetivo de diferenciar como grupo a los autores de esta época.

2 Los propios comienzos de la Antropología en España constituyen un problema historiográfico. Una muestra elocuente la encontramos en Ronzón (1991: 302-303), quien considera el Folklore como una Antropología evolucionista. 
entre ellas; también entroncaba con el interés científico surgido en el XIX por las variedades dialectales, que supuso, según opinión ampliamente aceptada, el nacimiento de la Dialectología y la Geografía Lingüística.

El Folklore no constituyó ninguna revolución o cambio de paradigma lingüístico, pero pudo estar en la base del desarrollo de las corrientes lingüísticas europeas que se manifestaron muy tímidamente a finales del XIX y eclosionaron definitivamente en el siglo XX; asimismo, pudo estimular indirectamente el interés específico por fenómenos que no habían sido tratados antes de forma sistemática y ordenada. Juzgamos, pues, conveniente situarnos en el contexto ideológico e histórico-social de la segunda mitad del siglo XIX en Europa, y en España en particular, para enjuiciar correctamente el conjunto de aportaciones del Folklore a la lingüística.

Analizaremos, en primer lugar, las bases epistemológicas de este movimiento y el concepto de lingüística que se manejó en su seno, en relación con los grandes avances de esta época en esta materia. En segundo lugar, mostraremos el lugar que ocupó lo lingüístico en la organización general y en la práctica de los estudios sobre el saber popular y expondremos la influencia que tuvo para el camino que siguió particularmente la lingüística española.

\section{Bases ideológicas del movimiento folklórico}

2.1. El interés erudito por el pueblo o lo popular hunde sus raíces en las postrimerías del siglo XVIII, en el contexto de la industrialización y del nacionalismo romántico. En esta época, los intelectuales burgueses percibieron el resquebrajamiento de las formas sociales tradicionales a causa de los avances introducidos por la Revolución Industrial, que supuso, entre otras cosas, la movilización de grandes masas de población del campo a la ciudad y la penetración de los adelantos técnicos en la vida cotidiana. La consiguiente polarización de las diferencias entre la cultura campesina y la cultura urbana contribuyó a que germinara un sentimiento de nostalgia por el desarraigo; al mismo tiempo generó un redescubrimiento del campo y del pueblo llano como un lugar y un modo de vida idílicos. Se desató, pues, un verdadero culto por lo popular en cualquiera de sus modalidades, cuya vertiente literaria es bien conocida: el surgimiento del género romántico del cuadro de costumbres en torno a 1830 responde a un deseo de describir y fijar lo tradicional o lo genuino del pueblo antes de su previsible desaparición como consecuencia del progreso.

Las palabras de William Henderson, uno de los primeros estudiosos que publicaron su obra en el marco de la Folk-lore Society de Londres, resumen a la perfección este sentimiento general heredado del Romanticismo: 
The age in which we live is remarkable, as in other points of view, so in this, that old habits and customs, old laws and sayings, old beliefs and superstitions, which have held their ground in the universal mind from the remotest antiquity, are fast fading away and perishing. We of the nineteenth century may congratulate ourselves on their disappearance; we may lament it, but the fact remains the same; and I for one will frankly acknowledge that I regret much which we are losing, that I would not have these vestiges of the past altogether effaced. It were pity that they should utterly pass away, and leave no trace behind. My heart as well as my imagination is too closely bound up with the sayings and doings which gave zest to the life of my forefathers, and so I became a Folk-Lore student before Folk-Lore came into vogue as a pursuit. (Henderson, 1879: vii)

En esta misma época, y en el marco político de las emergentes naciones europeas, la búsqueda de las manifestaciones culturales genuinas o auténticas de cada zona respondió además a la necesidad de apuntalar -o incluso crear en algunos casos- una identidad nacional, a partir de la idea de la existencia del genio particular de cada nación o pueblo, que Herder puso en circulación y asumieron los hermanos Grimm³ ${ }^{3}$. Este concepto terminó aplicándose a la lingüística con el concepto de forma interna (innere Sprachform) de las lenguas de Wilhelm von Humboldt (1767-1835), como recuerda Robins:

Nationalism, individualism, and libertarianism provided a favourable environment for new or intensified linguistic interests, the study of spoken forms and of non-literary dialects as truly popular manifestations of language, and the study of folklore. Language could be conceived not so much as a particularization of a universal structure, but primarily as moulded to the specific thought patterns of the speakers and reflecting their peculiar ways of thinking. Such an approach emphasized not universal, but differences between languages, and is found in Herder at the end of the eighteenth century; it culminates in Humboldt's tripartite linguistic typology and his conception of a specific innere Sprachform for each language. (Robins, 1975: 22)

2.2. Ya en la segunda mitad del siglo -particularmente entre 1850 y $1880-$ se asumió en Europa la filosofía positivista en el ámbito de la investigación científica. Nacido, como es sabido, a comienzos del XIX con el francés Auguste Comte (1798-1857) y difundido en Inglaterra por el inglés John Stuart Mill

3 Herder (1744-1803) sostenía que cada pueblo tenía su genio único y particular (Volkgeist), idea que fue después desarrollada por los hermanos August Wilhelm (17671845) y Friedrich von Schlegel (1772-1829). En el contexto alemán, la recuperación de esta identidad cultural histórica podría permitir la reunificación de los pueblos germánicos. Surgieron por ello personalidades que, como los hermanos Jacob (1785-1863) y Wilhelm Grimm (1786-1859), se afanaron en la recolección de tradiciones orales, en búsqueda de la esencia de ese 'genio del pueblo' perdido a causa de la preponderancia histórica de las élites. 
(1806-1873), el positivismo introdujo una metodología histórica inductista, que vinculaba la legitimidad de una interpretación a la existencia de abundantes y suficientes pruebas documentales. Comte se propuso organizar las ciencias en un orden lógico, desde la más abstracta, las Matemáticas, hasta la más concreta, la Sociología (palabra acuñada por él). Esta, según él, era solo posible en un 'estadio positivo' y la consideraba como la más importante de todas las ciencias".

Charles Darwin (1809-1882), por su parte, culminó su teoría de la evolución biológica con la publicación en 1859 de El origen de las especies -base de la biología moderna- en la que postuló que todas las especies de seres vivos evolucionaron con el tiempo a partir de un antepasado común mediante un proceso mecánico de supervivencia basado en la selección natural. Como es sabido, Darwin fue muy denostado en su época y sus ideas levantaron una gran polémica, pero su influencia fue enorme y no se limitó a las ciencias naturales, sino que fue igualmente importante para el pensamiento filosófico, social y religioso.

Precisamente una de sus extensiones fue el Evolucionismo social, especie de síntesis entre la teoría de la evolución de Darwin y la mentalidad positiva, cuyo máximo exponente fue Herbert Spencer (1820-1903) ${ }^{5}$. Para los evolucionistas sociales, la evolución natural constituía la clave que explicaba toda realidad, ya fuese biológica o relativa a las manifestaciones del espíritu. Delinear la evolución de la sociedad implicaría, por tanto, no solo conseguir entender mejor su esencia sino, en último término, enfrentarse con garantías a sus problemas y a su regeneración ${ }^{6}$. Esta teoría, también conocida como 'darwinismo social', impulsó enormemente la Sociología y la Antropología, aunque esta última se encaminaría después por otros derroteros ${ }^{7}$. Ahora bien, frente a los positivistas más puros, Spencer dejaba una puerta abierta a la religión, que quizá explica gran parte de su éxito internacional: no excluía la especulación sobre 'lo incognoscible', siempre que no se confundiera con el

4 Comte planteó una teoría del desarrollo humano y de la civilización en tres estadios: un 'estadio teológico', un 'estadio metafísico' y un 'estadio positivo' o 'científico', que consideraba como el adecuado para la reorganización social (Stromberg, 1995: 164).

5 Spencer fue el más célebre de los filósofos victorianos y uno de los pensadores más leídos en la época. Fue muy admirado por Darwin, quien eludió la cuestión de la evolución social humana al considerar que esta era tratada con enorme profundidad por el primero (Stromberg, 1995: 204).

6 "Se daba por sentado que los pueblos 'primitivos' representan el primer estadio en la escala del desarrollo, parangonable a la escala biológica; son nuestros antepasados del mismo modo que las formas de vida simples son los antepasados de la raza humana" (Stromberg, 1995: 200).

7 Como señalan Bonte e Izard (1996: 557), la Antropología moderna se configura precisamente a partir de la crítica al Evolucionismo. 
conocimiento de nivel científico. El Evolucionismo social tuvo una especial incidencia en España, pues los grupos liberales lo acogieron deseosos de evitar un conflicto irreductible entre las ideas científicas darwinistas, que denostaron con especial acritud (Núñez, 1977), y los acendrados sentimientos religiosos de la ideología imperante (vid. más adelante, 3.2).

Este fue el caldo de cultivo del movimiento folklórico. En él se confunden, por un lado, las ideas románticas de pueblo y nación y, por otro, el nuevo paradigma científico que se imponía en Europa a mediados de siglo a partir de la filosofía positivista comteana, los hallazgos de Darwin en el terreno de las ciencias naturales y la aplicación de ambas al estudio de las sociedades. Los folkloristas se apresuraron en la recuperación del saber popular, pero emprendieron esta tarea desde una perspectiva erudita y académica: en el último tercio del XIX justificaron con un punto de vista científico la mirada al pasado que con propósitos literarios o nacionalistas y con un espíritu nostálgico emprendieron los románticos desde principios de siglo.

\section{El movimiento folklórico y su incidencia en España}

3.1. El neologismo Folk-Lore, compuesto por dos raíces del alto germánico (folk, 'pueblo, gente, raza'; y lore, 'saber, ciencia'), fue acuñado por el filólogo, anticuario y arqueólogo William John Thoms (1803-1885) para dotar de un nombre técnico al estudio del 'saber popular' y distinguirlo del mero estudio de la literatura popular (conocido como popular antiquities o popular literature). Con el seudónimo de "Ambrose Merton", Thoms firmó una carta abierta titulada "Folk-lore" en el número 982 -correspondiente al 22 de Agosto de 1846- de la publicación periódica Athenaeum ${ }^{8}$, en la que instaba a los editores de la revista a que emprendieran el estudio del saber popular de forma sistemática, como actividad organizada y planificada, de manera que se mostrase así su verdadero valor?.

8 "Your pages have so often given evidence of the interest which you take in what we in England designate as Popular Antiquities, or Popular Literature (though by-the-bye it is more a Lore than a Literature, and would be most aptly described by a good Saxon compound, Folk-Lore,-the Lore of the People-) that I am not without hopes of enlisting your aid in garnering the few ears which are remaining, scattered over that field from which our forefathers might have gathered a goodly crop" (Thoms, 1846).

9 "The present century has scarcely produced a more remarkable book, imperfect as its learned author [Jakob Grimm] confesses it to be, than the second edition of the 'Deutsche Mythologie': and what is it? - a mass of minute facts, many of which, when separately considered, appear trifling and insignificant, —but, when taken in connexion with the system into which his master-mind has woven them, assume a value that he who first recorded them never dreamed of attributing to them" (Thoms, 1846). 
Esta empresa fue conceptualizada por los folkloristas en cierto modo como la 'etapa positivista' comteana antes aludida, es decir, la culminación de una serie de acercamientos anteriores a lo popular, que, a pesar de su valor, constituían meros antecedentes. Para ellos, el Folklore marcaba un antes y un después: así se intuye en las siguientes palabras de Guichot y Sierra (18601941) -participante y temprano cronista del movimiento folklórico español-, quien concede al movimiento romántico alemán un carácter preparatorio y a Inglaterra el protagonismo en la organización de la nueva ciencia popular:

Alemania fundó en la época del Romanticismo, la Mitografía, y en el subperiodo de preparación regionalista fundó la Demopsicología: representa la iniciación de ramas de la ciencia. Siguió Inglaterra, que en el subperiodo de preparación regionalista desenvolvió más la Mitografía, y en el subperiodo de preparación folklorista hizo la organización corporativa, la publicación de biblioteca nacional, y la fijación del concepto y del plan del Folklore: representa la creación de la ciencia entera. (Guichot y Sierra, 1922: 14)

En efecto, la primera sociedad organizada en torno al estudio del folklore fue la Folk-Lore Society ${ }^{10}$ de Londres, inaugurada en 1878 e impulsada por George Laurence Gomme ${ }^{11}$. En ella se dieron cita distinguidos científicos y etnógrafos de la época como Andrew Lang ${ }^{12}$, Sir Edward Burnett Tylor ${ }^{13}$ y el propio William J. Thoms. Desde su fundación se sucedieron diversas publicaciones metodológicas y epistemológicas así como múltiples discusiones teóricas encaminadas a la definición de la propia disciplina y de sus límites, de sus conceptos y su terminología ${ }^{14}$.

10 Esta Sociedad cumple ya más de un siglo de existencia. En 1958 pasó a eliminarse en el título el guion que separaba las dos raíces y se escribió como lo conocemos hoy: Folklore. Puede encontrarse más información en su página web: <www.folklore-society.com/aboutus/ index.asp>.

11 George Laurence Gomme (1853-1916) fue el primer Secretario de la Folk-Lore Society. Perteneció además a la Society of Antiquaries, a la Royal Statistical Society, al Anthropological Institute, la British Association, etc. Su Handbook of Folk-Lore, publicado en 1890 por la propia asociación, constituyó la primera guía pensada para orientar a los socios en la investigación folklórica.

12 Andrew Lang (1844-1912), erudito, escritor y crítico literario británico, fue un personaje altamente influyente en el ambiente literario de la segunda mitad del siglo XIX. No es conocido tanto por su propia producción literaria cuanto por sus compilaciones de cuentos de hadas, siguiendo la línea iniciada por los hermanos Grimm en Alemania.

13 Edward Burnett Tylor (1832-1917) aplicó el evolucionismo al estudio antropológico de las culturas primitivas de México. Llegó a ser miembro de la Royal Society de Gran Bretaña y catedrático de Antropología en Oxford.

14 Vid. Hartland, Wake, Wheatley y Gomme (1884), Burne, Machado y Hartland (1885), Cox (1895), Hartland (1904). El propio término Folklore planteó una fuerte controversia: por ser formación neológica, contradecía en cierto modo, según algunos, el concepto mismo que representaba. Por ello se acunaron otros términos que no llegaron a 
Toda esta actividad sirvió de estímulo para la adhesión de investigadores en otros países del mundo occidental. El movimiento se extendió con fuerza a Portugal, Italia, Francia y España ${ }^{15}$ gracias a la acción en cada caso de una o varias personalidades carismáticas, que no solo se dedicaron de forma entusiasta a su planificación y organización sino que también teorizaron acerca de la nueva ciencia (doctrina, sentido, división, etc.), fundaron revistas especializadas y ayudaron a consolidar su estimación científica. Algunas de estas figuras destacadas fueron Adolfo Coelho ${ }^{16}$, Teófilo Braga ${ }^{17}$, José Leite de Vasconcelos ${ }^{18}$ o António Thomaz Pires ${ }^{19}$ en Portugal, Giuseppe Pitré ${ }^{20}$ en Italia y Paul Sébillot ${ }^{21}$ en Francia. Asimismo, se impulsaron sociedades que imitaban a la inglesa, como la Societé des traditions populaires (París, 1885), el Folklore italiano (1884), The American Folklore Society (Cambridge, Massachusetts, 1888), la Verein für Volkskunde (Berlín, 1901), la Verein für Volkskunde (Viena, 1894), la Schweizerische Gesellschaft für Volkskunde (Zürich, 1896), la Hessische Vereinigung für Volkskunde (Gießen, 1901), amén de otras muchas iniciativas de carácter regional o local.

Así, frente a otras posibles manifestaciones anteriores de interés por la cultura popular, puede decirse que el Folklore fue un movimiento gestado desde la Modernidad, como señala Velasco Maíllo (1990), en tanto que nació organizado, institucionalizándose en forma de sociedades y medios de expre-

suplantarlo. En el caso español se propusieron Demótica, Demosofía, Demopsicología, Demopedia, etc. (vid. Marcos Arévalo, 1988: X-XI).

15 Guichot (1922) registra también ramificaciones más tímidas en otros países o zonas europeas, como Dinamarca, Noruega, Suecia, Finlandia, Laponia, Bélgica, Holanda y Suiza, así como en otros continentes.

16 Adolfo Coelho (1847-1919) fue profesor universitario en la Facultad de Letras de la Universidad de Lisboa y es reconocido como el introductor en Portugal del método histórico-comparativo desarrollado por la romanística alemana. Destaca en esta línea su obra A lingua portuguesa. Noções de glottologia geral e especial portuguesa (1868).

17 Teófilo Braga (1843-1924) es conocido tanto por su labor política (llegó a ser presidente de la República Portuguesa) como por su faceta ensayística sobre filosofía, sociología, etnografía y literatura.

18 José Leite de Vasconcelos (1858-1941) es una referencia fundamental para la filología, la etnografía y la arqueología portuguesas. Realizó la primera monografía importante de la dialectología del portugués, a la que se dedicó sobre todo en su primera época, y fundó revistas señeras para la disciplina como la Revista Lusitana (1887).

19 Thomaz Pires (1850-1913) nació en Elvas y es autor de múltiples libros sobre literatura popular del Alemtejo: Cantos populares portuguezes en dos volúmenes (1902 y 1905), Cancioneiro popular político: trovas recolhidas da tradição oral (1891). También publicó varios trabajos recopilatorios sobre comparaciones alentejanas.

20 Giuseppe Pittré (1841-1916) fue el fundador y director del Archivio per le tradizioni popolari en Palermo, uno de los medios de expresión de los folkloristas.

21 Paul Sébillot (1843-1918), pintor, etnólogo y dialectólogo bretón, fundó la Revue des Traditions Populaires en Francia. 
sión oficiales (revistas, manuales, sedes permanentes, conferencias, reuniones y congresos, comidas, etc.) y tuvo la virtud de aunar esfuerzos y unificar el sentido y los métodos de las investigaciones que se iban a llevar a cabo. Gozó desde sus comienzos de un incuestionable estatus científico, debido a su marcado carácter no solo erudito sino universitario. De hecho, se buscó siempre el cultivo e integración de esta práctica como materia en los planes de estudio de los centros superiores de enseñanza, donde se leyeron tesis y trabajos de investigación (vid. por ejemplo, Kaindl, 1903: 42).

3.2. Durante la segunda mitad del siglo XIX, en España se desarrollan al mismo tiempo la Antropología y el Folklore. Quizá no pueda establecerse una separación nítida entre ambas desde el punto de vista epistemológico, pero a la luz de los resultados y de su influencia actual, terminaron polarizando su objeto de estudio. La Antropología, que se desarrolla en los medios liberales y republicanos de Madrid, Andalucía y las Canarias cuenta entre sus iniciadores con naturalistas y médicos que invocaron el darwinismo y las corrientes evolucionistas. El Folklore, que bebió de estas mismas fuentes, pareció vincularse más directamente con las corrientes regionalistas y nacionalistas de inspiración herderiana, y se dedicó preferentemente al estudio de los particularismos y, en especial, de la literatura popular.

El inspirador y canalizador de todo el movimiento fue, sin duda, Antonio Machado y Álvarez, "Demófilo" (1848-1893). En él confluyen todas las tendencias antes apuntadas, gracias al entorno familiar y académico en el que pudo desarrollar sus actividades. Como es sabido, el darwinismo encontró graves obstáculos en España, pero su padre, Antonio Machado y Núñez (18151896), que llegó a ser rector de la Universidad de Sevilla en el Sexenio Revolucionario (1868-1873) 22 y miembro de la Sociedad Antropológica de Sevilla (creada en 1871), fue uno sus primeros difusores en nuestro país desde su cátedra de Ciencias Naturales en la Universidad de Sevilla, y publicó tempranos trabajos de divulgación de las nuevas ideas en la Revista Mensual de Filosofía, Literatura y Ciencias de Sevilla, como recuerda Núñez:

Las características mismas que rodean la introducción del darwinismo en España constituyen ya de por sí un dato muy revelador de la situación científica del país. Como muestra, en primer lugar, de esa decidida voluntad de puesta al día por parte de determinadas minorías científicas, de que hace poco hablábamos, se pueden citar los nombres de varios naturalistas que

22 Este período, inaugurado con la Revolución de septiembre de 1868, "la Gloriosa", creó una atmósfera de libertad que facilitó la difusión de las corrientes de pensamiento que ya se habían implantado en Europa: se dieron a conocer las obras de Darwin, Krause, etc. y se realizaron las primeras traducciones al español de estas. 
comenzaron a hablar del transformismo muy pocos años después de la aparición de El origen de las especies. Tenemos noticias de que el profesor Antonio Machado y Núñez -abuelo del poeta- solía comentar en sus cursos de Historia Natural de la Universidad de Sevilla, allá en los inicios de la década de 1860, la nueva teoría transformista. Lo mismo cabría decir de Rafael García Álvarez, catedrático de Historia Natural en el Instituto de Segunda Enseñanza de Granada y uno de los principales difusores del darwinismo en nuestro país. Otro testimonio de este conocimiento temprano de la teoría darwinista en España lo tenemos también, aunque sea por vía de contrarios, en los numerosos ataques que se le empiezan a prodigar en los discursos de apertura de curso en las universidades. (Núñez, 1977: 24-25)23

Demófilo heredó el progresismo ideológico de su padre y recibió las ideas del Krausismo de su maestro Federico de Castro $^{24}$, quien le inspiró, además, un interés científico e ideológico por la literatura popular. Su primer contacto con Madrid (1867-1869), donde terminó los estudios universitarios de Derecho iniciados en Sevilla, terminó de modelar su espíritu y su formación intelectual: allí entró en contacto con las figuras más importantes del krausismo español y con los inspiradores de la Institución Libre de Enseñanza (Federico de Castro, Nicolás Salmerón, Manuel de la Revilla, Francisco Giner de los Ríos) (vid. Pineda Novo, 1991: 171 y ss.).

Antes de conocer la existencia del Folklore como movimiento organizado, Machado emprendió varias actividades en torno a la cultura popular. Impulsó varias publicaciones periódicas, en cuyo espíritu puede reconocerse su propia evolución ideológica: la Revista Mensual de Filosofía, Literatura y Ciencias (18691874), creada por su padre y por su mentor, Federico de Castro, fue una publicación que gozó de gran prestigio y sirvió de medio de expresión para románticos, liberales y krausistas en Sevilla durante el Sexenio Revolucionario (18691873). En ella comienza a publicar sus recopilaciones y apreciaciones sobre lite-

23 También lo señala Abellán (1988: 93): "La penetración de las ideas de Darwin en España se ve muy favorecida por la libertad de expresión reinante a partir de la Revolución de 1868. Antes de ese año apenas se habla de Darwin ni se mencionan sus teorías, salvo contadas excepciones. Entre ellas las de Antonio Machado y Núñez -abuelo del poeta- que, desde su cátedra de Historia Natural de la Universidad de Sevilla, propagó las teorías transformistas". Existe una edición facsímil de un discurso de García Álvarez (Sequeiros, 2009).

24 Federico de Castro (1834-1903) es considerado el introductor del pensamiento de Krause en Andalucía, que tanta repercusión tuvo en nuestro país. La ideología krausista influye en la interpretación del positivismo en España, frena su impacto y lo combina con la metafísica en la construcción de un nuevo orden social, en una síntesis que se conocerá como krausopositivismo y que se asocia con la Institución Libre de Enseñanza (Capitán Díaz, 1985: 109 y ss). Algunos autores de la época, reacios en cierto modo a abandonar el krausismo, destacaron las analogías entre el pensamiento de Krause y el de Spencer, llegando incluso a afirmar que el último no añadió nada nuevo (vid. Portolés, 1986). 
ratura, fonética y fraseología popular ${ }^{25}$. Inmediatamente después de su desaparición, funda una revista decenal de marcado carácter progresista llamada La Enciclopedia (1877-1883) ${ }^{26}$, en la que contempló secciones científicas de Filosofía, Ciencias Naturales, Lingüística, Etnografía, Ciencias Sociales y Derecho, pero potenció especialmente una sección específica sobre Literatura Popular. En ella mostró "una nueva dirección en sus estudios y sentido filosófico, con tendencia evolucionista, predominantemente spenceriana" (Sendras y Burín, 1892: 283; vid. también Velasco Maíllo, 1988).

El prestigio que alcanzó La Enciclopedia permitió a Demófilo darse a conocer ante influyentes intelectuales de la época con los que compartía su interés por la literatura popular ${ }^{27}$ y le facilitó el contacto con la Folklore Society, tras lo cual se propuso fundar una sociedad análoga en España, a la que consiguió dar carta de naturaleza con la publicación de sus bases el 3 de noviembre de 1881 con el nombre de Folklore Español. Ideó, no obstante, un plan de actuación por provincias ${ }^{28}$ : por ello, tan solo veinte días después de hacer públicas estas bases, el 28 de noviembre de 1881 constituyó el Folk-lore Andaluz y su amigo Luis Romero y Espinosa hizo lo propio en Extremadura el 11 de junio de 1882 con

25 Estos apuntes serán publicados posteriormente en el tomo V de El Folklore Español: Biblioteca de las Tradiciones Populares Españolas (los lingüísticos: "Modismos populares", p. 27; "fonética andaluza", 43-51; "coplas refranescas", 58-64; "coplas sentenciosas", 6771; "Antinomia entre un refrán y una copla", 73).

26 Pineda Novo (1991: 48-49) recoge los nombres de gran parte de los participantes: colaboradores habituales de esta publicación fueron Antonio Sendras y Burín, Federico Barbado, Jacobo Laborda, Miguel Corbacho, Francisco Rodríguez Marín, Juan Antonio Torres y Salvador, Luis Romero de Espinosa, Javier Lasso de la Vega, Manuel Jiménez, Fernando de Castro, Luis Sotomayor, Francisco Ruiz Esteve y Felipe Pérez y González; esporádicamente participaron Manuel Sales y Ferré, José María Sbarbi, Federico de Castro, Manuel Milá y Fontanals, Francisco Giner de los Ríos, Joaquín Costa, Antonio María García Blanco, etc.

27 "Bastará que recuerde que la dió á conocer á Europa entera, con grandísimo entusiasmo, el ilustre profesor de la Universidad de Graz (Austria) Hugo Schechardt [sic], que á poco de haber comenzado á publicarse la sección llegó á Sevilla y buscó con interés á Machado, felicitándole cariñosamente. En breve tiempo, y merced á la galantería del Sr. Schechardt [sic], Machado y los que con él cultivaban los estudios de literatura popular, estaban en relación con el erudito bibliotecario de Weimar Reinhold Köler, con Pitré, Gastón Paris, Sabatini, Braga, Coello, la señorita Coronedi Berti y con cuantas personalidades eminentes se consagraban en Europa á este género de estudios. La Enciclopedia alcanzó entonces una reputación en el extranjero, y frecuentemente era citada con encomio y juzgada con aplauso por el Polibiblion, la Meluzine, Der Magazin für die Literatur der, In-und-Auslandes, la Rivista de Letteratura Popolare, publicaciones todas de autoridad y prestigio, cuyos desinteresados elogios servían para estimular más y más á los redactores de la sección" (Sendras y Burín, 1892: 284).

28 Machado organizó los estudios folklóricos españoles por provincias, a partir de aquellos lugares donde se encontraba alguna personalidad afín al movimiento que facilitase la investigación: se incluían las distintas regiones de la península pero también las colonias (Filipinas, Cuba, Puerto Rico). 
el Folk-lore Frexnense ${ }^{29}$. Gracias a su empeño, se crearon otras sociedades en Galicia, Castilla, Navarra, La Rioja, etc. En 1883 inició una nueva aventura editorial con la Biblioteca de las Tradiciones Populares Españolas (1883-1886). Llegó a alcanzar una cátedra como profesor de la Ciencia del Folk-lore en la Institución Libre de Enseñanza en el curso 1885-86.

La actividad folklórica avanzó siempre por el empuje de Demófilo, que realizó una intensa labor de propaganda y buscó adeptos por toda la geografía española. Pero nunca tuvo la importancia que sí pareció alcanzar en otras latitudes y careció no solo de medios sino también de interés por parte de la intelectualidad española, lo que, unido a las dificultades financieras y familiares de Machado, terminó por minar su confianza en el proyecto (Pineda Novo, 1991). A la altura de 1894, tras la prematura muerte de Machado el año anterior, la empresa del Folklore español se percibía como un fracaso entre los propios folkloristas y Rodríguez Marín no duda en denominarlo "fiasco":

Con mala estrella nacieron el Folk-Lore Andaluz, el Bético-Extremeño y cuantos se fundaron en España, á costa de los patrióticos esfuerzos de nuestro inolvidable compañero D. Antonio Machado y Álvarez y de las contadísimas personas que le auxiliábamos. Mal germinó aquella semilla, á pesar de la buena voluntad de los sembradores; poco vivió aquella planta, que, bien mirado, sólo tenía de exótica su nombre anglo-sajón, y que ha prevalecido en los demás países cultos de Europa, hasta el punto de creer necesaria Mr. Carnoy la publicación de un Dictionnaire international des traditionnistes contemporains.

Tú y yo sabemos, de sobra, á qué causas se debió tal fiasco; pero ni tú ni yo hemos dejado de ser folk-loristas, y uno y otro seguimos recogiendo y estudiando cantos populares, cuentos, refranes, supersticiones..., empresa tanto más meritoria, cuanto que la experiencia nos ha persuadido de que en España no hay público numeroso á quien agrade esta clase de trabajos literarios, ni, por consiguiente, editores para ellos. (Rodríguez Marín, 1894, Carta dedicatoria a "Micrófilo")

El empuje de los folkloristas españoles consiguió prolongar su actividad, ya como empresa personal y ajena a toda organización, durante las tres primeras décadas del siglo siguiente, pero se vio frenada casi definitivamente por la Guerra Civil, dado que, según apunta Rodríguez Becerra (1999), "las personas identificadas con esta tarea se exiliaron o fueron reprimidas, las instituciones suspendidas y cualquier preocupación por el saber del pueblo fue considerado sospechoso". En efecto, los representantes más notorios de la antropología y el folklorismo fueron reprimidos a causa de sus ideas evolucionistas y su antidogmatismo, e incluso por la sospecha de alentar separatismos regionales (Prat i Carós, 2004: 15).

29 Actualmente existen ediciones facsimilares de las aportaciones de ambas Sociedades, tanto de El Folk-lore Andaluz (Blas Vega y Cobo, 1981), como del Folk-lore Frexnense y Bético-extremeño (Marcos Arévalo, 1987). 


\section{La investigación en torno al lenguaje y las lenguas}

En el programa folklorista estuvo siempre presente el estudio del lenguaje popular, aunque no recibió, sin embargo, la misma atención en todos los países. En algunos casos el camino fue más fácil, pues los folkloristas asimilaron pronto el influjo de la Filología Comparada y la Dialectología y orientaron su quehacer en esta línea. En otros casos no se dieron las condiciones intelectuales o ideológicas adecuadas, como ocurrió en España, donde hubo más reticencias ante el empuje del nuevo paradigma científico que se comenzaba a imponer en Europa.

4.1. En las clasificaciones globales de los estudios folklóricos que se plantearon en Inglaterra, país fundador del movimiento, figura invariablemente el estudio del lenguaje popular, pero puede observarse cierta evolución en los planteamientos específicos sobre esta materia. En 1859 -una década después de la carta de William John Thoms, antes citada- se edita una selección de artículos de la revista semanal Notes and Queries (fundada por el propio Thoms) dedicada específicamente al "Folklore": en las páginas preliminares se explica la organización por materias de las aportaciones, entre las que se incluyen específicamente las de "popular and proverbial sayings (their origin, meaning, and application)" y "philology (including local Dialects, Archaisms, and Notes on our old Poets)" (Thoms (ed.), 1859). Más tarde, una vez fundada la Folk-lore Society, se sucedieron diversas clasificaciones en su seno, en las cuales también se cita, bajo distintos nombres, el estudio del lenguaje popular. Sintetizamos en el cuadro 1 estas clasificaciones ${ }^{30}$ :

\begin{tabular}{|c|c|c|}
\hline AUTOR & SECCIÓN O RAMA & OBJETO DE ESTUDIO \\
\hline \multirow{2}{*}{ Nutt (1884) } & Folk-wit & "Proverbs, riddles, jests, local sayings, and quips" \\
\hline & Folk speech & "Philology, grammar, rhetoric, and metre" \\
\hline \multirow[t]{2}{*}{ Hartland (1884) } & \multirow[t]{2}{*}{ Folk-thought } & $\begin{array}{l}\text { "Folk-wit" ("proverbs"; "local and personal saws, and prophecies"; } \\
\text { riddles") }\end{array}$ \\
\hline & & "Folk-speech" \\
\hline \multirow{3}{*}{ Gomme (1890) } & \multirow{3}{*}{ Folk-Sayings } & "Jingles, Nursery Rhymes, Riddles, \&c." \\
\hline & & "Proverbs" \\
\hline & & "Nicknames, Place Rhymes" \\
\hline \multirow{2}{*}{ Burne (1914) } & \multirow{2}{*}{ Sayings } & "Proverbs and Riddles" \\
\hline & & "Proverbial Rhymes and Local Sayings" \\
\hline
\end{tabular}

\section{CUADRO 1}

30 Para una exposición detallada de estas clasificaciones, vid. Montoro del Arco (2009b). La clasificación de Nutt se halla en Nutt y Gomme (1884: 311-315); la de Hartland en Hartland, Wake, Wheatley y Gomme (1884: 340-344). Burne ofrece su clasificación en 1914, aunque ya había hecho algunas apreciaciones al respecto en 1886. 
Como se puede ver, Alfred Nutt utiliza específicamente en 1884 los términos de filología y gramática para explicar los contenidos del folk speech, rama que, en cierto modo, se presentaba como la contrapartida formal del folk-wit o ingenio popular; sin embargo, tiene serias dudas sobre sus competencias en este aspecto: el Folklore había nacido como una ciencia que trataba de indagar en la psicología del pueblo, de modo que, aunque se nutría de materiales lingüísticos, de ellos interesaba el contenido o sustancia. Así se explica la propuesta de Hartland, quien considera el "habla popular" como una parte del "pensamiento popular"31. Esta diferencia es expresada, de hecho, por el propio Nutt, quien valiéndose de la dicotomía entre lo "fisiológico" y lo "psicológico", no manifiesta muchos reparos a 'ceder' el ámbito de lo formal a otros investigadores (los "filólogos"), no tanto porque no le interese, sino por reconocer que existen profesionales mejor cualificados para ello:

It will be seen that I give a very much wider scope to the word folk-lore than is usual, and that I look upon as legitimately belonging to it subjects with which the Society has never dealt. I feel some doubt about my class 8 . If the study of speech be really, as many philologists hold, a physiological rather than a psychological science, it should be excluded on the same ground upon which I have already excluded biology. In any case it may be practically excluded, as its interests are already well cared for by active and capable workers. But the Society should, I maintain, look upon the other seven classes as its province. (Nutt, 1884: 312)

En efecto, los antropólogos ingleses que fundaron el Folklore no solo conocían las innovaciones de la gramática histórica y comparada ${ }^{32}$, sino que se basaron en sus leyes para la reconstrucción del pasado cultural: gracias a la reflexión sobre la clasificación genética de las lenguas indoeuropeas, la Filología contribuyó de forma definitiva a la definición de la disciplina antropológica y el modelo filológico fue aplicado al estudio de la mitología, las religiones $\mathrm{y}$, en general, de las sociedades más remotas u orientales. Algunos comparatistas fueron, de hecho, filólogos y antropólogos: el alemán Max

31 Los propios términos alternativos al de Folklore atendían también a la filosofía o la psicología, no a la lengua como mecanismo (Demosofía, Demopsicología, etc.).

32 Conviene recordar que el filólogo alemán Jakob Grimm (1785-1863), considerado su fundador, formuló en su Deutsche Grammatik (1819) la ley de los cambios de los sonidos indoeuropeos en las lenguas germánicas y encontró regularidades en las analogías fonéticas ("ley de Grimm"). La primera gramática comparada de las lenguas románicas fue publicada en los años 1836-1844 por Friedrich Diez (1794-1876) y el método comparativo fue perfeccionado por August Schleicher (1821-1868), quien aplica definitivamente el paradigma positivista en los estudios lingüísticos, hasta el punto de que la segunda mitad del siglo XIX se construye casi sin excepciones a partir del paradigma schleicheriano, si bien con notables excepciones como la de Hugo Schuchardt (Koerner, 1989). 
Müller (1823-1900), por ejemplo, -filólogo y fundador, a la sazón, de la Mitología Comparada- mantuvo un largo debate en Oxford a finales de la década de 1880 con el folklorista Alfred Lang, discípulo de Tylor, que no aceptaba la idea del surgimiento de los dioses por una transformación del alma y mostraba la necesidad de un acercamiento en términos de cultura (Bonte e Izard, 1996: 544).

La distinción entre lo fisiológico y lo psicológico, de hecho, fue polarizándose cada vez más en el ámbito de la Filología hasta que las leyes fonéticas de los Junggrammatiker, o neogramáticos, imprimieron un carácter inmanente al modelo de los primeros comparatistas y situaron en un segundo plano todos aquellos aspectos que están en relación con las coordenadas en las que funcionan los sistemas lingüísticos, esto es, los factores sociales, la cultura o el contexto, etc. (Jankowsky, 2001). Los trabajos comparados, por tanto, derivaron hacia un estudio sobre todo de la forma y, como consecuencia de ello, de la fonética de las lenguas, y dirigieron la Filología por caminos distintos a los que la vinculaban con la Antropología, la Etnolingüística y la Sociología. En este momento, de hecho, surge la necesidad de teorizar sobre la diferencia entre Filología y Lingüística (Koerner, 1997: 170-171). Prueba de que se sentían como realidades diferentes es el hecho de que Gomme (1890) y Burne (1914), bastantes años después de la fundación de la Folklore Society, no contemplen ya la Filología como rama de los estudios populares, pues reducen la parte lingüística del programa folklorista a lo que denominan sayings, esto es, proverbios y unidades afines (cf. Gomme, 1890).

En suma, los folkloristas ingleses fueron conscientes de los nuevos derroteros por los que se dirigía la investigación lingüística y construyeron o perfilaron su objeto de estudio tratando de no inmiscuirse en el de las nuevas tendencias que comenzaban a extenderse en la época. Aceptaron tácitamente la mayor competencia de los 'lingüistas' o 'filólogos' en el plano fisiológico y su labor fue limitándose poco a poco al registro de múltiples y valiosos datos, susceptibles de ser estudiados, eso sí, desde otros puntos de vista. Redujeron su interés a los 'productos' lingüísticos populares en los que podía encontrarse el pensamiento o el ingenio del pueblo, pero no se afanaron en vincular estos materiales a la reconstrucción de lenguas y al estudio de los dialectos. Aunque no dejaron nunca de lado el estudio de la lengua, se volcaron en la vertiente antropológica y literaria de su programa: así lo muestra la lista de publicaciones auspiciadas hasta la fecha por la Folklore Society ${ }^{33}$.

33 Disponible en la página web de dicha sociedad: <www.folklore-society.com/aboutus/ index.asp> [Consulta: 12/3/2010]. 
4.2. Otra de las disciplinas con las que el Folklore mantuvo una estrecha relación fue la Dialectología. Para los primeros romanistas, los dialectos eran formas degeneradas de la lengua y la recogida de datos dialectales de tipo sincrónico era tan solo un principio auxiliar de la investigación, conducente a la verificación de las leyes fonéticas de transformación que explicaban el cambio lingüístico. Sin embargo, pronto el rastreo de la variabilidad lingüística fue prevaleciendo sobre la búsqueda de regularidades y terminó conformando toda una disciplina, la Dialectología, que encaminó su estudio también hacia la forma (fonética).

El estudio de las variedades dialectales había tenido un desarrollo temprano en Francia y los folkloristas, conscientes de ello, la sintieron también como una parcela distinta a la del Folklore. Por eso Alejandro Guichot y Sierra deslinda el estudio de los dialectos del del folklore en la revisión que hace en 1920 del movimiento folklorista europeo, bajo un elocuente subepígrafe titulado "La lingüística independiente":

La numerosa bibliología de las ramas de la Lingüistica también la suprimiremos en este libro: diferente esta ciencia de la del Folklore, e independiente desde el siglo XVIII. A partir de aquellas «Memorias sobre las lenguas, dialectos, y jergas, tanto de Francia como de los demás países», que en 1834 comenzó a publicar la Sociedad de Anticuarios de Francia ${ }^{34}$, la producción de estos estudios se aumentó en todo el mundo, adquiriendo mayor desarrollo con la Filología comparada, ya entrada la segunda mitad del siglo XIX. Resulta lista abrumadora de obras, monografías y estudios sobre los idiomas inferiores, los dialectos populares, las hablas vulgares, y hasta las jergas particulares. (Guichot y Sierra, 1922: 12)

En efecto, la Société royale des Antiquaires de France, nombre con el que se conoció a partir de 1814 la antigua Académie Celtique, se ocupó, tras la reforma de sus reglamentos, del estudio y reconstrucción de la historia de Francia a partir de los vestigios que el paso del tiempo había respetado. En su seno se acordó además, como señala Pop (1950: 16), prestar una atención especial "aux études sur les langues, idiomes et patois", con lo que impulsaron definitivamente el estudio de la variación lingüística. Cuando prendió la rama folklorista, la Dialectología tenía ya un largo recorrido, de forma que Folklore y Dialectología se percibían como disciplinas diferentes (aunque sin unos límites precisos). Así se desprende, por ejemplo, de las palabras de la sección "Cronique" del número 4 de la revista Romania (fundada en 1872 y

34 Literalmente, "de recherches sur les langues, la géographie, la chronologie, l'histoire, la littérature, les arts et les antiquités celtiques, grecques, romaines et du moyen âge, mais principalement des Gaules et de la nation française jusqu'au xvıe siècle inclusivement" (Pop, 1950). 
dedicada a las lenguas y literaturas romances), dirigida por Paul Meyer y Gaston Paris, donde se establece una significativa distinción entre el estudio dialectal y el folk-lore, actividades que persiguen un mismo fin:

Nous sommes heureux de voir que de divers côtes on répond à l'appel que nous avons adressé: des études sur les patois, des vocabulaires, des recueils de chansons et de contes nous ont été envoyés ou promis. Il est à désirer que l'exemple de nos collaborateurs soit imité dans toute la France: nul n'ignore en effet que les langues populaires sont partout menacées par la terrible concurrence du français, et que d'autre part le folk-lore, pour employer un mot anglais heureusement formé qui nous manque, va s'effaçant de jour en jour dans l'oubli. (Vieweg, 1875: 159)

No obstante lo anterior, los folkloristas franceses realizaron estudios claramente dialectológicos: el propio Paul Sébillot, al tiempo que coleccionaba cantos populares bretones, se dedicó al estudio del dialecto bretón: en 1878, con motivo de la Exposición Universal de París, presentó una carte linguistique de la Bretagne, y publicó en ese mismo año varios trabajos sobre los límites del bretón y el francés y sobre la extensión de las lenguas célticas (Sébillot, 1878 ; 1886). Estos estudios coinciden con los de los autores que el canon historiográfico reconoce como auténticos iniciadores de la Dialectología, tales como Jules Guilliéron (1854-1926) -formado en la escuela de G. Paris (Iordan, 1967: 24) - o el abate Rousselot (1846-1924). Este último publicaba en 1887 su primer estudio programático para el estudio de los patois y destacaba su valor para el conocimiento de las lenguas históricas y, en general, del pasado de la humanidad y de las distintas sociedades, compartiendo así con los folkloristas la urgente necesidad de empeñarse en la labor de recuperación del pasado popular antes de su desaparición:

Chaque année qui s'écoule emporte avec elle des sons, des constructions, des mots dont la perte est irréparable. Il faut donc se hâter de sauver ce qui a été épargné jusqu'ici. C'est une oeuvre qui intéresse la science et l'honneur du pays. Plusieurs l'ont senti, et les ouvrages sur les patois se sont multipliés. On doit rendre hommage à ces patriotiques efforts, ainsi qu'aux pouvoirs publics et aux societés savants qui les ont encourages et soutenus. Mais, il faut bien le reconnaître, ce qui a été fait est bien peu en comparaison de ce qui reste à faire. (Rousselot, 1887: 3)

La sintonía entre dialectólogos y folkloristas era evidente, como confirma también el método empleado para la recogida de datos, el cuestionario, y para la presentación de los materiales, esto es, la elaboración de atlas. La geografía folklórica, como señala Iordan (1967: 491-493), fue especialmente cultivada en Alemania y en Suiza. El proyecto del Deutscher Sprachatlas iniciado por Georg Wenker (1852-1911) y continuado por su discípulo Ferdinand Wrede cons- 
tituyó el modelo en el que se basó en 1907 el iniciador del Deutsche Volkskunde-Atlas (ADV), Wilhelm Pessler (Pop, 1950: 753 y ss.). Igualmente, los folkloristas suizos Paul Weiger y Richard Weiss, gracias al magisterio de la escuela lingüística y dialectológica de J. Jud y K. Jaberg ${ }^{35}$, emprendieron en 1936 la elaboración del Atlas der schweizerischen Volkskunde, amparados por la Schweizerische Gesellschaft für Volkskunde.

4.3. En definitiva, a pesar de todo, en muchas partes siguió considerándose el estudio de la gramática y de los dialectos como una competencia del Folklore. Así lo encontramos, por ejemplo, en la obra del alemán Elard Hugo Meier (1898), Deutsche Volkskunde, quien organiza los contenidos de su manual por conceptos tales como los tipos de poblaciones, la casa o los cuentos y poesías populares, pero también dedica una amplia sección al estudio de la fonética, la gramática y el léxico, tanto de los dialectos como del habla popular ("Die Volksprache und die Mundarten", págs. 276-311).

La mayor o menor imbricación entre Lingüística, Dialectología y Folklore dependió en gran medida de las circunstancias históricas de cada país. Así, en Portugal se hizo especial hincapié en la parte lingüística (glotológica) del Folklore debido al contacto directo de los responsables del folklore lusitano con la Filología Comparada, como en el caso de Adolfo Coelho (vid. Boléo, 1948). La empresa folklórica fue impulsada en este país por un nutrido grupo de investigadores cuyos intereses científicos giraron particularmente en torno al estudio lingüístico en combinación con el etnológico ${ }^{36}$, como muestra una de sus principales medios de expresión, la Revista Lusitana, fundada por Leite de Vasconcellos en 1887. Este, en el prólogo al primer número, supedita el estudio de la Filología y de la Etnología al progreso del país, pues, en sintonía con la filosofía evolucionista spenceriana, delinear la evolución de la sociedad portuguesa facilitaría su regeneración. Se hace eco igualmente de la necesidad de adoptar para ello los principios de la verdadera ciencia:

O objecto d'esta publicação não é una simples curiosidade de colleccionadores; teem-se em vista os altos intereses da sciencia, e ao mesmo tempo

35 El Sprach- und Sachatlas Italiens und der Südschweiz, dirigido por los filólogos suizos Karl Jaberg (1877-1958) y Jakob Jud (1882-1952) y publicado entre 1928 y 1940, fue el primer atlas lingüístico que tuvo en cuenta las cosas junto a las palabras correspondientes. 36 La segunda generación de antropólogos en Portugal es la que se implica directamente en el Folklore y estuvo formada por un conjunto de investigadores (Adolfo Coelho, Consiglieri Pedroso, Teófilo Braga, Tomás Pires, Leite de Vasconcelos, Manuel Veigas Guerreiro, etc.) que, como se ha dicho, hicieron especial hincapié en el estudio de la lengua popular. Ejemplos de aplicación de la corriente evolucionista a otros aspectos son los Elementos de antropología (1881) de J. P. Oliveira Martins o el estudio sobre los gitanos titulado Os Ciganos em Portugal. Com um estudo sobre calâ (1892) de Coelho (vid. Bonte e Izard, 1996: 604). 
fins perfeitamente praticos. A renovação intelectual, por que o presente seculo está pasando, impõe a todos os países, que pẽnsão, o dever de contribuir como o seu obulo para o progresso geral, porque non solum um pane vivit homo, - e o espirito bem orientado sente uma necessidade impreterivel de çonhecer profundamente as relações dos phenomenos quer physicos, quer sociaes; isto é, não póde escusar, a sciencia.

[...]

Sem o conhecimento da Philologia, é impossivel o estudo perfeito da grammatica, e por consequencia a comprehensão de uma das faculdades mais nobres do homem, -a linguagem; sem o conhecimento de Ethnologia, muitos factos de literatura e de historia ficão na sombra, e andaremos como que ás cegas, ignorando uma grande parte dos nossos caracteres e das nossas origens. (Leite de Vasconcellos, 1888-89: I-II).

\section{Folklore y lingüística en España}

En España el impulso folklorista estuvo marcado sobre todo por eruditos interesados preferentemente por el estudio de la literatura, pero no se perdió nunca el interés por la sección lingüística del Folklore. Machado siempre consideró parte de sus estudios como lingüísticos y, a pesar de la heterogeneidad de sus intereses, mantuvo dentro de sus objetivos esta vertiente ${ }^{37}$. Las clasificaciones españolas de las ramas del folklore así lo atestiguan (vid. cuadro 2), pues incluyeron siempre un apartado específico de Lingüística ("Glotología") o de "Gramática popular", frente a las clasificaciones de sus colegas europeos (vid. cuadro 1), donde lo lingüístico se fue viendo reducido a la recogida de proverbios.

\begin{tabular}{|c|l|l|}
\hline AUTOR & SECCIÓN O RAMA & \multicolumn{1}{c|}{ OBJETO DE ESTUDIO } \\
\hline \multirow{3}{*}{ Machado (1883) } & $\begin{array}{l}\text { Glotologia, } \\
\text { Gramática popular }\end{array}$ & $\begin{array}{l}\text { "Las locuciones, giros, traba-lenguas, frases hechas, motes y apodos, } \\
\text { modismos, provincialismos y voces infantiles; los nombres de sitios, } \\
\text { pueblos y lugares, de piedras, animales y plantas" }\end{array}$ \\
\hline & Literatura popular) & "Refranes" [junto con "canciones, romances, cuentos"] \\
\cline { 2 - 3 } Guichot (1922) & Gramática popular & $\begin{array}{l}\text { "Parlario" (Locuciones, giros, frases hechas, modismos, } \\
\text { provincialismos, motes, apodos, rimas, retintines, trabalenguas, } \\
\text { voces infantiles; habla y fonética generales") }\end{array}$ \\
\cline { 2 - 3 } & $\begin{array}{l}\text { Nomenclatura } \\
\text { popular }\end{array}$ & $\begin{array}{l}\text { "Nombres y designaciones de sitios y lugares, de grupos y } \\
\text { poblaciones, de piedras, plantas y animales, de fenómenos naturales; } \\
\text { habla y fonética generales" }\end{array}$ \\
\hline
\end{tabular}

\section{CUADRO 2}

37 "Creo que he dicho también que los artículos de La Epoca van encaminado[s] a atraer a los señores a este género de estudios: en ellos me he ocupado del Folk-Lore, hasta ahora, bajo distintos puntos de vista: el prehistórico y naturalista, el demo-psicológico, el lingüístico y el demo-topográfico" (Carta de 7 de noviembre de 1883, apud Steingress (comp.), 1996: 95). 
Las coordenadas históricas e ideológicas de la época personalizaron enormemente la empresa folklorista española. Como se ha señalado más arriba, hubo en general un gran rechazo al paradigma científico darwinista, debido fundamentalmente al inmovilismo propio de la ideología religiosa imperante. Como consecuencia, tampoco llegaron de forma inmediata las nuevas tendencias de la lingüística, dado que el prejuicio ideológico condujo a una intensa actitud antipositivista, "según la cual la lengua, siendo un don de Dios, no es científicamente estudiable" (Alonso-Cortés, 1992: 514; vid. también Gutiérrez Cuadrado, 1984; y Bernardo 1996) ${ }^{38}$.

En una época en la que literatura, lingüística y cultura no estaban tan claramente deslindadas, los folkloristas españoles, merced a su espíritu progresista, canalizaron las nuevas ideas y establecieron un inesperado puente con la romanística a través del filólogo austríaco Hugo Schuchardt (1842-1927) y el concepto de lingüística que manejaron estuvo mediatizado por esta valiosa amistad (Weiss, 1981).

Schuchardt empezó sus estudios con Schleicher y los continuó con Diez, siguiendo la tradición de la gramática histórica y comparada. Fue miembro de la generación que formó la corriente de los neogramáticos, pero se mantuvo independiente y hasta llegó a criticarlos por la rigidez de sus leyes. Perfeccionó el método palabras y cosas (Wörter und Sachen), creado por Rudolf Meringer ${ }^{39}$, por el que se vinculaban precisamente los dos aspectos que parecían dividir a filólogos y folkloristas en Inglaterra: lo fisiológico y lo psicológico, la forma y el contenido. La lengua, según su concepción, es una creación del individuo y por ello refleja su vida, su carácter y su cultura. Así, consideró que para el estudio de las palabras era indispensable examinar también la historia de las cosas, ya que las palabras sólo existían relacionadas con estas y su conocimiento garantizaría conclusiones más fiables sobre su origen.

Parece que fue el naturalista Salvador Calderón y Arana (1851-1911), colaborador de la Institución Libre de Enseñanza, quien, durante una estancia en Viena, instruyó a Schuchardt en el español y le recomendó a determinados intelectuales vinculados a la Institución, tales como Giner de los Ríos, Valera, Núñez de Arce o Menéndez Pelayo. A su llegada a Madrid en febrero de 1879,

38 El método histórico-comparativo, de hecho, llegaría a España de la mano de Ramón Menéndez Pidal y tendría su máximo esplendor durante la primera mitad del siglo XX (Portolés, 1986).

39 Schuchardt prefería denominarlo Sachen und Wörter ('cosas y palabras'), al considerar que las cosas existían por sí solas antes que las palabras. La revista Wörter und Sachen. Kulturhistorische Zeitschrift für Sprach- und Sachforschung, fundada en 1909 por el propio Meringer y por Wilhelm Meyer-Lübke, desplazó definitivamente la opción terminológica del profesor austríaco (cfr. Iordan, 1967: 112). 
estos contactos fueron el germen de la relación de Schuchardt con Demófilo y los demás miembros de La Enciclopedia, en cuya compañía estuvo durante su estancia en Sevilla hasta el verano de ese mismo año. Amplió los intereses de Demófilo, apegado especialmente a la literatura popular, y desató en él la pasión por las lenguas como manifestación viva de los pueblos ${ }^{40}$. El filólogo austríaco animó a los folkloristas españoles a que abrazaran la teoría evolucionista y, de hecho, en La Enciclopedia se tradujeron algunos pasajes de la obra de Spencer ese mismo año, antes incluso del contacto con los folkloristas europeos. En ella Machado redacta casi un manifiesto evolucionista:

No basta decir existe una literatura popular y sus formas son tales o cuales: es necesario estudiar esas formas y señalar su naturaleza y eslabonamiento con las anteriores y siguientes: no cabe tampoco dar, verbigracia, una teoría científica del cuento, la copla o el refrán, sin conocer los cuentos, refranes y coplas; esto pudo pasar en otros tiempos, pero no en los presentes, en que sabemos que las cosas sólo llegan a entenderse estudiándolas, y en que el prestigio y el valor de las afirmaciones dogmáticas va de vencida. Las coplas no han de estudiarse por bonitas, ni los trovos por caprichosos, ni las adivinanzas por ingeniosas, ni por raras y curiosas las tradiciones y leyendas: coplas, adivinanzas, tradiciones, leyendas, trovos, adagios, refranes, proverbios, diálogos, juegos cómicos, cuentos, locuciones peculiares, frases hechas, giros, etc., han de estudiarse como materia científica. (Machado y Álvarez, La Enciclopedia 10 abril de 1879, apud Guichot, 1922: 163)

A pesar de su firme propósito, las reticencias de sus compañeros fueron fuertes y, en su correspondencia con el austríaco, Machado mostró continuamente su desazón por no conseguir su propósito ${ }^{41}$.

Como es sabido, el profesor austríaco se sirvió de un corpus de transcripciones de coplas flamencas recopiladas por Machado para su aproximación a la fonética andaluza (Schuchardt, 1990 [1881]). Igualmente, los animó también a realizar trabajos de fonética dialectal, pues quedaron impresionados con la nueva disciplina (cf. Viudas Camarasa, 1992). El propio Machado había mostrado su interés por la fonética en sus tempranas y rudimentarias incursiones en la fonética andaluza, e incluyó en su clasificación del Folklore

40 "[...] Por estas y otras razones, Schuchardt se convirtió en algo así como el spiritus rector de la futura empresa folklorista sevillana al ampliar y estimular el interés literario de Demófilo y sus compañeros hacia la filología y la lingüística como ciencias modernas: fue, por decirlo así, observador crítico y apoyo logístico en cuanto al «nacimiento» del «FolkLore Andaluz» se refiere" (Steingress (comp.), 1996: 15-16).

41 "Por más que he hecho me ha sido imposible conseguir de los jóvenes de La Enciclopedia que sigan sus acertados e inteligentes consejos: gracias que he logrado que cambien el tamaño y que vayan inclinándose poco a poco a la teoría de la evolución" (Steingress (comp.), 1996: 72). 
español un apartado de "fonética popular" en su división (vid. cuadro 2). Sin embargo, los folkloristas, a pesar de su interés, no se consideraban capacitados para esta labor. El propio Machado lo señala en múltiples ocasiones en su correspondencia con Schuchardt, a quien reconoce su poca formación en este tipo de estudios:

Esperamos con impaciencia la continuación de sus artículos sobre fonética andaluza y la indicación de algunas obras donde pudiéramos aprender algunas nociones de fonética. (Sin fecha núm. 06760, apud Steingress (comp.), 1996: p. 72)

Dentro de pocos días (un mes o cosa así) le remitiré una coleccionista de cantes flamencos; por supuesto que queda V. incapacitado para decir que no sabemos fonética después de dejarnos con la miel en los labios como decirse suele y venirnos con malecitos de nervios. Nada; V. es un picarón y para vengarme no le envío los carteles hasta que continúe su trabajo de fonética andaluza que está como los santos padres esperando el Santo Advenimiento. (Carta de 25 de octubre de 1880, apud Steingress (comp.), 1996: 74. Subrayado en el original)

Su desconocimiento de la lengua alemana contribuyó incluso a incrementar su desesperación:

Era necesario que nos tradujesen su monografía Die Can[es] fl[amencos] para que viéramos en ella las nocioncitas de Fonética que trae al final. ¿Hay alguna obrita nueva y breve de esta ciencia traducida al francés? -estamos fastidiados sin saber alemán; pero no tenemos tiempo, ni virtud para estudiarlo.- (Carta de 1882, apud Steingress (comp.), 1996: 90. Subrayado en el original)

Una vez inaugurada la Sociedad del Folklore Español, le pide que abandere este estudio con la creación de un Folklore Austríaco -que fue fundado más tarde, y en Viena, por Michael Haberlandt y Wilhelm Hein-, para impulsar, entre otras cosas, el estudio de la fonética que, según él, era escaso entre los folkloristas:

Ms. Sébillot se propone, según nos anunció, la creación del Folk-Lore francés; [...] Por qué no se hace V. el promovedor del Folk-Lore austríaco y procuramos reunirnos en París el año 1884? La verdad es que la Fonética es el lado débil, el flaco de todos los folkl-loristas europeos y convendría un FolkLore en que se diera impulso a estos descuidados estudios. (Carta de 18 de febrero de 1882, apud Steingress (comp.), 1996: 88. Subrayado en el original)

Sin embargo, los folkloristas andaluces se lanzaron a la recogida de materiales sin planificación. Se basaron en sus propias observaciones, hicieron entrevistas directas en las salidas al campo y excursiones y también cuestionarios a distancia, que eran rellenados por los corresponsales que tuvieron en las diferentes provincias. La falta de una metodología científica era más que 
evidente y, por ello, Machado propuso a Schuchardt la elaboración de un mapa dialectológico de España, empresa en la que ellos, aceptando sus limitaciones, se limitarían a recoger los materiales:

Desde tu punto de vista o sea el de la fonética y dialectología, creo haber estado en lo cierto al haber dividido la sociedad en varios centros. ¿Han debido ser 16 o debieran ser más o menos? He aquí lo que yo no sé y lo que es preciso que tú nos enseñes comprometiéndote solemnemente a hacer el Mapa dialectológico de España, dándote nosotros los datos que tú vayas pidiendo. Como tú eres un socio nuestro, esto es, folklorista español, es necesario que hagas que nuestro F[olk]-L[lore] eche la pata (aventaje) al F[olk]L[lore] Francés y al Italiano, al menos en la parte filológica que corre a tu cargo. (Carta de 10 de mayo de 1885, apud Steingress (comp.), 1996: 98. Subrayado en el original)

El trabajo de Schuchardt sobre las hablas andaluzas no se considera hoy día un estudio realmente científico, pues no se basaba en un corpus fiable ni en estudios de campo. Aparte, no tuvo mucha difusión en España y tardó en ser traducido. El estudio de las particularidades andaluzas se centró más bien en la recopilación de locuciones y refranes, tarea en la que los folkloristas se emplearon a fondo y en la que destacó especialmente el sevillano Francisco Rodríguez Marín (Montoro del Arco, 2008; 2009a: 2009b). El gracejo, gracia o, en fin, peculiaridad tópica de los andaluces tuvo al menos un efecto positivo: congregó el interés de determinados eruditos por su estudio. Y esto contribuyó definitivamente a que los dialectólogos se fijaran en él en primer lugar: los primeros trabajos de fonética dialectal sobre el español se fijan en el andaluz, como "La frontera del andaluz", a cargo de Tomás Navarro Tomás, Aurelio M. Espinosa y Lorenzo Rodríguez-Castellano (1933); y el primer atlas regional de España, el Atlas Lingüístico y Etnográfico de Andalucía (ALEA) se proyectó en Andalucía y dotó a la geografía lingüística española de un marcado carácter etnográfico.

La empresa folklorista dejó su sello, pues, en la primera mitad del siglo XX, período marcado por la labor de la llamada escuela filológica de Madrid, bajo el magisterio de Menéndez Pidal. En su personalísima visión de la filología, ocupa un importante lugar el folklore, pues, como afirma Garatea (2005: 23), "conforme avanza en sus investigaciones y en la comprobación de sus tesis, [Menéndez Pidal] invade pausadamente casi todas las áreas que toman parte en la labor filológica: la edición de textos, paleográficos y críticos, la etimología, la gramática histórica, la dialectología, el folklore, la historia de las instituciones y de las costumbres". Sus trabajos sí han pasado al canon historiográfico general de la filología española y, por ende, son más conocidos. En todo caso, el estudio de la impronta del folklore en la lingüís- 
tica española de este período, que cuenta con hitos tan representativos como la creación en 1944 de la Revista de Dialectología y Tradiciones Populares, excede los límites planteados para este artículo.

\section{Conclusión}

La Historiografía de la Lingüística, tal y como se concibe desde los años setenta del siglo XX, recomienda acompañar la lectura de los textos de la tradición con el estudio del "clima de opinión" que los rodea, esto es, la atmósfera intelectual del período en el que surgieron las ideas contenidas en ellos. Desde hace tiempo se ha señalado el extraordinario valor que tienen las fuentes no prototípicas en la tarea interpretativa del historiógrafo. Es indudable que contribuyen a conocerla mejor; pueden incluso llegar a cambiar nuestra percepción de la historia del pensamiento lingüístico ${ }^{42}$.

La ciencia folklórica estuvo en su momento a la vanguardia de la investigación científica europea y se gestó al mismo tiempo que disciplinas como la Gramática histórica y comparada o la Dialectología, con las que coincidió en el interés por el estudio de lo que algunos denominaron "lenguaje popular". Muchos lingüistas de la época fueron abiertos iniciadores, seguidores, defensores o simplemente cultivadores de la nueva ciencia folklórica e incluso se erigieron como representantes de ella en sus respectivos países; otros, más comprometidos con otros ámbitos del programa folklorista, realizaron también incursiones en materia lingüística aunque de forma tangencial. En el caso español, la mayoría de los folkloristas 'declarados' no fueron auténticos lingüistas y no dedicaron su labor específicamente a esta parcela del conocimiento, pero no por desinterés, sino porque no sabían realmente cómo abordarlo: su entusiasmo chocó con frecuencia con su manifiesta falta de formación, a consecuencia de las reticencias que la intelectualidad española tuvo ante las novedades ideológicas europeas, particularmente aquellas que podían cuestionar las creencias religiosas. Como resultado, en sus obras lingüísticas apenas se incluyen partes analíticas o reflexión teórica en general en torno a su objeto de estudio, sino que se dedicaron preferentemente a la recopilación notarial de abundantes datos, confiando en que, en un futuro no muy

42 "Toda esta documentación, sin ser objeto central de la Historiografía de la lingüística, en el caso del canon/cánones, se constituyen -según otra de nuestras hipótesis de investigación- como fuentes fundamentales que ayudan, e incluso revolucionan, la nómina de obras, autores, etc. tradicionalmente incluidos en el/los canon/cánones y, consecuentemente, modifican de forma sobresaliente la propia percepción y descripción de la historia del pensamiento lingüístico (en tanto que datos estrictamente objetivos)" (Zamorano, 2009: 252). 
lejano, pudiesen ser la base para estudios científicos de mayor enjundia. Así interpretamos, por ejemplo, su abundante producción paremiológica y fraseológica (vid. Montoro del Arco, 2009b). En suma, mantuvieron latente la necesidad de abordar este tipo de trabajos en virtud de la admiración que les suscitaron las disciplinas que estaban a la vanguardia de la investigación en Europa, y ello contribuyó sin duda a la creación de un clima de opinión favorable a este tipo de estudios, que terminaría fructificando ya en el siglo XX.

\section{Referencias bibliográficas}

Abellán, José Luis (1988): Historia crítica del pensamiento español. 5/I La crisis contemporánea (1875-1936). Madrid, Espasa Calpe.

Alonso-Cortés, Ángel (1992): Lingüística general. Madrid, Cátedra.

Bernardo Paniagua, José $\mathrm{M}^{\mathrm{a}}$. (1996): "Historia de la ciencia e historia de la lingüística”. En E. Serra Alegre y otros (eds.), Panorama de la Investigació a l'Estat Espanyol (Actes del I Congrés de Lingüistica General). Valencia, Universitàt de València, vol. IV, págs. 5-12.

Blas Vega, José y Eugenio Cobo (eds.) (1981): El Folk-Lore andaluz (Edición Conmemorativa del Centenario). Sevilla, Tres-Catorce-Diecisiete.

Boléo, Manuel de Paiva (1948): "Adolfo Coelho e a filologia portuguesa e alemã no século XIX”, Biblos XXIII, págs. 607-691.

Bonte, Pierre y Michel Izard (1996): Diccionario Akal de etnologia y Antropología. Madrid, Akal.

Burne, Charlotte Sophie (1886): "Classification of Folk-Lore", The Folk-Lore Journal 4/2, págs. 158-163.

Burne, Charlotte Sophie (1914): The handbook of Folklore (edition revised and enlarged by Charlotte Sophia Burne, vice-president, and sometime president, of the Folklore Society). Londres, Published for the Folk-Lore Society by Sidgwick \& Jackson.

Burne, Charlotte Sophie, Antonio Machado y Álvarez y Edwin Sidney Hartland (1885): "The Science of Folk-Lore", The Folk-Lore Journal, 3/2, págs. 97-121.

Capitán Díaz, Alfonso (1985): Historia de la educación en España. Madrid, Ministerio de Educación y Ciencia.

Cox, Marian Roalfe (1895): An Introduction to Folk-lore. Londres, D. Nutt.

Garatea Grau, Carlos (2005): El problema del cambio lingüistico en Ramón Menéndez Pidal: el individuo, las tradiciones y la historia. Tübingen, Gunter Narr.

Gomme, George Laurence (ed.) (1890): The Handbook of Folklore. London, Publications of The Folklore Society.

Guichot y Sierra, Alejandro (1922): Noticia histórica del folklore. Orígenes en todos los paises hasta 1890. Desarrollo en España hasta 1921. Sevilla, Hijos de Guillermo Álvarez, Impresores. 
Gutiérrez Cuadrado, Juan (1984): "Darwin en la lingüística española del siglo XIX". En M. Hormigón Blánquez (coord.), Actas del II Congreso de la Sociedad Española de Historia de las Ciencias, vol. 1. Zaragoza, Sociedad Española de Historia de las Ciencias, págs. 429-448.

Hartland, Edwin Sidney ( $\left.{ }^{2} 1904\right)$ : Folklore: What is it and what is the Good of It? Londres, D. Nutt.

Hartland, Edwin Sidney, C. Staniland Wake, Henry B. Wheatley y George Laurence Gomme (1884): "Folk-Lore Terminology", The Folk-Lore Journal, 2/11, págs. 340-348.

Henderson, William (1879): Notes on the Folk-Lore of the Northern counties of England and the borders. Londres, W. Satchell, Peyton and Co.

Iordan, Iorgu (1967): Lingüística Románica. Evolución-corrientes-métodos (reelaboración parcial y notas de Manuel Alvar). Madrid, Ediciones Alcalá.

Jankowsky, Kurt R. (2001): "The consolidation of the neogrammarian framework". En S. Auroux, E. F. K. Koerner, H.-J. Niederehe y K. Versteegh (eds.): An International Handbook on the Evolution of the Study of Language from the Beginnings to the Present. Berlín/Nueva York, Walter de Gruyter, págs. 1350-1367.

Kaindl, Raimund Friedrich (1903): Die Volkskunde. Ihre Bedeutung, ihre Ziele und ihre Methode. Leipzig/Viena, Franz Deuticke.

Koerner, E. F. Konrad (1989): "August Schleicher and Linguistic Science in the second half of the 19th Century". En Practicing Linguistic Historiography. Selected essays. Amsterdam/Philadelphia, John Benjamins, págs. 79-100.

Koerner, E. F. Konrad (1997): "Linguistics vs Philology: self-definition of a field or rhetorical stance?", Language Sciences, 19/2, págs. 167-175.

Leite de Vasconcellos, José (1888-89): "Prólogo", Revista Lusitana, I, págs. 1-2.

Machado y Álvarez, Antonio (1882): "Introducción”, Folk-lore Andaluz, 1, págs. 1-8.

Machado y Álvarez, Antonio (1883): "Introducción”. En Folklore español. Biblioteca de las tradiciones populares españolas, vol. 1, págs. V-XIII.

Marcos Arévalo, Javier (1987): "El Folklore y la Revista Frexnense y Bético-Extremeña. Estudio preliminar". El Folk-lore frexnense y bético-extremeño. Órgano temporal de las Sociedades de este nombre. 1883-1884. Fregenal, Imprenta de El Eco, págs. I-XXXVI. Meier, Elard Hugo (1898): Deutsche Volkskunde. Estrasburgo, Karl J. Trübner.

Montoro del Arco, Esteban Tomás (2008): "Positivismo y folclore: la aportación a la fraseología de Francisco Rodríguez Marín (1855-1943)”. En Becerra Hiraldo, J. $\mathrm{M}^{\mathrm{a}}$. y Torres Montes, J., Estudios de lengua española. Homenaje a José María Chamorro Martínez, Granada: Editorial Universidad de Granada, págs. 201-211.

Montoro del Arco, Esteban Tomás (2009a): "El lugar de Francisco Rodríguez Marín (1855-1943) en la historia de la Fraseología española". En García, J. Ma . (coord.), Las ideas y realidades lingüísticas en los siglos XVIII y XIX. Cádiz: Servicio de publicaciones de la Universidad de Cádiz, págs. 531-549.

Montoro del Arco, Esteban Tomás (2009b): "La relevancia del movimiento internacional del Folk-lore para el desarrollo de la Fraseología en España". En Eilers, V., 
K. Süselbeck y Wieland, K. (eds.): Aspectos del desarrollo de la lingüística española a través de los siglos. Hamburgo, Buske, págs. 67-83.

Navarro Tomás, Tomás, Aurelio M. Espinosa y Lorenzo Rodríguez Castellano (1933):

"La frontera del andaluz", Revista de Filología Española, XX, págs. 225-277.

Núñez, Diego (1977): El darwinismo en España. Madrid, Castalia.

Nutt, Alfred y George Laurence Gomme (1884): "Folk-Lore Terminology", The FolkLore Journal, 2/10, págs. 311-316.

Pineda Novo, Daniel (1991): Demófilo: vida y obra del primer flamencólogo español. Madrid, Cinterco.

Pop, Sever (1950): La dialectologie: aperçu historique et méthodes d'enquêtes linguistiques. Louvain, J. Duculot.

Portolés, José (1986): Medio siglo de filología española (1896-1952). Positivismo e idealismo. Madrid, Cátedra.

Prat i Carós, Joan (coord.) (2004): Antropología y Etnología. Madrid, Editorial Complutense y Caja de Ahorros de Madrid (Colección Las ciencias sociales en España, 2).

Real Academia Española (2001): Diccionario de la lengua española (=DRAE). Madrid, Espasa-Calpe http://www.rae.es.

Robins, R. H. (1975): "Some Continuities and Discontinuities in the History of Linguistics". En H. Parret (ed.), History of Linguistic Thought and Contemporary Linguistics. Berlín, De Gruyter, págs. 13-32.

Rodríguez Becerra, Salvador (1999): "El Folklore, ciencia del saber popular. Historia y estado actual en Andalucía”, Revista de Folklore, 19b, págs. 75-80: http://www. funjdiaz.net/folklore/07ficha.cfm?id=1812 (15.01.09).

Rodríguez Marín, Francisco (1894): Cien refranes andaluces: de Meteorología, Cronología, Agricultura y Economía rural. Recogidos de la tradición oral y concordados con los de varios países románicos/ por Francisco Rodríguez Marín (Segunda edición anotada). Sevilla, Imp. de E. Rasco.

Ronzón, Elena (1991): Antropología y antropologías. Ideas para una historia crítica de la antropología española. El siglo XIX. Oviedo, Pentalfa Ediciones.

Rousselot, Jean (1887): "Introduction à l'étude des patois", Revue des patois galloromans, I, págs. 1-22.

Schuchardt, Hugo (1990 [1881]): Los cantes flamencos (die Cantes flamencos) (ed., trad. y coment. de Gerhard Steingress, Eva Feenstra, Michaela Wolf). Sevilla, Fundación Machado.

Sébillot, Paul (1878): "Sur les limites du breton et du français, et les limites des dialectes bretons", Bulletins d'Anthropologie (séance du 6 juin 1878), págs. 236-247.

Sébillot, Paul (1886): "La langue bretonne, limites et statistiques", Revue d'Ethnographie, V, págs. 1-29.

Sendras y Burín, Antonio (1892): "Antonio Machado y Álvarez (Estudio biográfico)", Revista de España, 141, págs. 279-291. 
Sequeiros Sanromán, Leandro (2009): Granada y el darwinismo: discurso de Rafael García Álvarez (1872) y la censura sinodal de 1872. Granada, Universidad de Granada.

Steingress, Gerhard (comp.) (1996): Cartas a Schuchardt (la correspondencia inédita de los folkloristas y otros intelectuales españoles con el romanista y lingüista Hugo Schuchardt. Sevilla, Fundación Machado.

Stromberg, Roland N. (1995): Historia intelectual europea desde 1789. Madrid, Debate. Thoms, William J. (1846): "Folk-Lore", The Athencum, 22 de agosto de 1846.

Thoms, William J. (1859): Choice notes from "Notes and Queries": Folk Lore. Londres, Bell and Daldy.

Velasco Maíllo, Honorio M. (1988): "El Evolucionismo y la evolución del Folklore. Reflexiones a propósito de la historia del Folklore extremeño", El Folk-lore Andaluz, 2, págs. 13-32.

Velasco Maíllo, Honorio M. (1990): "El folklore y sus paradojas”, Revista Española de Investigaciones Sociológicas, 49, págs. 123-144.

Vieweg, F. (1875): "Cronique", Romania, IV, págs.158-160.

Viudas Camarasa, Antonio (1992): "Fonética extremeña en el siglo XIX". En M. Ariza, J. Ma Mendoza, R. Cano, y A. Narbona (eds.), Actas del II Congreso Internacional de Historia de la Lengua Española, vol. 2. Madrid, Pabellón de España, págs. 291-299.

Weiss, Brigitta (1981): "Hugo Schuchartd y el mundo hispánico", Thesaurus XXXVI/2, págs. 205-229.

Zamorano Aguilar, Alfonso (2009): "Epihistoriografía de la Lingüística y Teoría del Canon". En M. Veyrat Rigat y E. Serra Alegre (eds.), La lingüística como reto epistemológico y como acción social. Estudios dedicados al profesor Ángel López García con ocasión de su sexagésimo aniversario, vol. 1. Madrid, Arco Libros, págs. 209-220. 